\title{
FDA Application Type Terminology
}

National Cancer Institute

\section{Source}

National Cancer Institute. FDA Application Type Terminology. NCI Thesaurus. Code C123270.

Terminology used in the framework of identifying types of pharmaceutical application types. 